\title{
Inhibition of photosynthesis in Melia azedarach and Ligustrum lucidum induced by manganese toxicity using OJIP chlorophyll $a$ fluorescence transient
}

\author{
M.S. LIU**, X.H. HUANG ${ }^{* *}$, R.J. WANG ${ }^{* * *}$, H.Y. XU ${ }^{* *}$, and F. ZHU*, \\ College of Landscape Architecture and Art Design, Hunan Agricultural University, 410128 Changsha, China* \\ College of Life Science and Technology, Central-South University of Forestry and Technology, 410004 Changsha, \\ China $^{* *}$ \\ Guangxi Key Laboratory of Superior Trees Resource Cultivation, Guangxi Zhuang Autonomous 11 Region Forestry \\ Research Institute, Nanning, China ${ }^{* * *}$
}

\begin{abstract}
Manganese ( $\mathrm{Mn})$ excess is a major abiotic stress for plant growth. In the present study, we investigated the effects of $\mathrm{Mn}$ on photosynthesis in Ligustrum lucidum and Melia azedarach leaves using chlorophyll fluorescence transients. Both plant species were exposed to two Mn concentrations $(0.5$ and $1 \mathrm{mmol})$ for 10 and $30 \mathrm{~d}$. Results showed that excess Mn significantly inhibited photosynthesis. With the increase of Mn concentration and stress time, the inhibition was more serious. Mn stress impaired PSII at the donor and the acceptor side by damaging the oxygen-evolving complex and limiting electron transport downstream of $\mathrm{Q}_{\mathrm{A}}$ in both trees. A significant decline in $820 \mathrm{~nm}$ reflection curve absorption was observed in $M$. azedarach, suggesting that the oxidization-reduction reactions in PSI were inhibited but this phenomenon was not observed in L. lucidum. Therefore, excess Mn impaired the whole electron transport chain associated with inactive PSII reaction centers in Ligustrum lucidum and inhibited oxidizationreduction reactions in PSI in $M$. azedarach.
\end{abstract}

Keywords: energy conversion efficiency; heavy metal stress; JIP-test; OJIP curve.

\section{Highlights}

- Nonstomatal factors reduced $\mathrm{CO}_{2}$ assimilation of Ligustrum lucidum and Melia azedarach under Mn excess

- Mn excess caused the damage to PSII oxygen-evolving system in both species

- Ligustrum lucidum might be more tolerant to Mn stress than Melia azedarach
Received 17 July 2020

Accepted 18 January 2021

Published online 18 February 2021

Corresponding author

e-mail: csuftzf@163.com

phone: 8615873162712

fax: $0731-85623458$

Abbreviations: ABS/RC - absorption flux (of antenna Chls) per RC (also a measure of PSII apparent antenna size); $\mathrm{CE}$ - carboxylation efficiency; $C_{\mathrm{i}}$ - intercellular $\mathrm{CO}_{2}$ concentration; $\mathrm{DI}_{0} / \mathrm{RC}$ - dissipated energy flux per $\mathrm{RC}$ at $\mathrm{t}=0 ; \mathrm{F}_{0}-$ minimal fluorescence yield of the dark-adapted state; $F_{J}$ - fluorescence intensity at the J-step $(2 \mathrm{~ms}) ; F_{K}$ - fluorescence intensity at $300 \mu \mathrm{s} ; \mathrm{F}_{\mathrm{M}}$ - maximum fluorescence yield of the dark-adapted state; $\mathrm{F}_{\mathrm{V}} / \mathrm{F}_{\mathrm{M}}$ - maximum quantum use efficiency; $g_{\mathrm{s}}$ - stomatal conductance; IP-phase - the efficiency of electron transport around the PSI; $\mathrm{M}_{0}$ - approximated initial slope of the fluorescence transient; $\mathrm{MR}_{0}$ - first reliable recorded fluorescence at $0.7 \mathrm{~ms} ; \mathrm{MR}_{\min }$ - the minimum fluorescence intensity; OEC - oxygen-evolving complex; $\mathrm{PI}_{\mathrm{ABS}}$ - performance index; $P_{\mathrm{N}}-$ maximum net photosynthetic rate; $\mathrm{RE}_{0} / \mathrm{RC}$ - the flux of electrons transferred from $\mathrm{Q}_{\mathrm{A}}{ }^{-}$to final PSI acceptors per PSII at $\mathrm{t}=0 ; \mathrm{S}_{\mathrm{m}}-$ normalized total complementary area above the OJIP transient (reflecting single-turnover $\mathrm{Q}_{\mathrm{A}}$ reduction events); $\mathrm{TR}_{0} / \mathrm{RC}_{\mathrm{C}}$ trapped energy flux (leading to $\mathrm{Q}_{\mathrm{A}}$ reduction) per $\mathrm{RC}$ at $\mathrm{t}=0 ; \mathrm{V}_{\mathrm{PSI}}-$ maximum decrease in slope in the range of $0.7-3 \mathrm{~ms}$ of $\mathrm{MR} / \mathrm{MR}_{0} ; \mathrm{V}_{\mathrm{PSI}+\mathrm{PSII}}-$ maximum increase in slope in the range of $7-300 \mathrm{~ms}$ of $\mathrm{MR} / \mathrm{MR}_{0} ; \delta_{\mathrm{R} 0}-$ efficiency with which an electron can move from the reduced intersystem electron acceptors to the PSI end electron acceptors; $\Phi_{\mathrm{E} 0}$ - quantum yield for electron transport; $\psi_{\mathrm{E} 0}$ - probability that a trapped exciton moves an electron into the electron transport chain beyond $\mathrm{Q}_{\mathrm{A}}$.

Acknowledgements: This research was funded by the National Natural Science Foundation of China (32072672), the Key Research and Development Project of Hunan Province (2017NK2171), the Scientific Innovation Fund for Post-graduates of Central South University of Forestry and Technology (20181007), and the Scientific Innovation Fund for Post-graduates of Central South University of Forestry and Technology (CX20192062).

Conflict of interest: The authors declare that they have no conflict of interest. 


\section{Introduction}

With the extension and enhancement of human activities, such as mining and industrial disposal (He et al. 2012), heavy metals have become a worldwide concern. In nature, heavy metals are difficult to degrade in soil, so they can exist in soil for a long time. Plants growing in metal-contaminated areas show several disturbances related to physiological and biochemical processes, such as photosynthesis (Demmig-Adams et al. 2017). Photosynthesis is a process by which plants convert light energy into chemical energy to produce sugars and other organic compounds (Qiao et al. 2012). Plants affected by heavy metals have shown inhibition of stomatal conductance $\left(g_{\mathrm{s}}\right)$, photosynthetic rate $\left(P_{\mathrm{N}}\right)$, carboxylation efficiency $(\mathrm{CE})$, and activity of PSI and PSII, leading to reduced plant growth and biomass.

The disruptive effect of heavy metals on plant photosynthesis is a common phenomenon observed in a wide range of plants (Li et al. 2010, Moradi and Ehsanzadeh 2015). Many studies (Miyata et al. 2015, Huang et al. 2018) have shown that PSII, as the first protein complex in light-dependent reactions, is very sensitive to heavy metal stress. The damage caused by heavy metals to PSII includes that on the donor side (Dewez et al. 2005), the acceptor side (Barón et al. 1995), and the reaction centers (Fodor 2002). Previous studies have found that copper stress damages the oxygen-evolving complex (OEC) (Rijstenbil et al. 1994) and the electron transport of PSII (Yruela et al. 1996), resulting in a reduction in the quantum efficiency of PSII. The positive O-step, J-step, L-band, and $\mathrm{K}$-band in chlorophyll $(\mathrm{Chl}) a$ fluorescence transients were observed in Mn-treated Citrus grandis seedlings, suggesting that Mn impairs PSII behavior (Li et al. 2010). Gururani et al. (2013) have reported that the positive K-bands and L-bands appear under heavy metal stress. Che et al. (2018) observed that under stress from excess copper, the Chl fluorescence transient curves change from OJIP to OKJIP. The positive K-band and the reduction of proteins of the OEC suggest that excess copper damages the OEC at the donor side of PSII and affects the activity of PSII. Liang et al. (2019) have reported that excess Mn inhibits PSII electron transport from the donor side to the acceptor side, which may be caused by the damaged OEC in L. lucidum. It has been also reported that damage caused by $\mathrm{Cd}$ toxicity on electron transport occurs on both the donor and acceptor sides of PSII (Sigfridsson et al. 2004). Farmer and Mueller (2013) found that heavy metals inhibit PSII and increase the production of ${ }^{1} \mathrm{O}_{2}$. At the same time, the stress also causes the photoinhibition of the PSII (Aranjuelo et al. 2014, Yang et al. 2020). When the absorption of light is more than light requirments for photosythesis, singlet oxygen is produced in PSII which can cause photoinhibition of PSII. Pätsikkä et al. (1998) found that excess copper caused photoinhibiton of PSII for the electron transport from the donor side to $\mathrm{P}_{680}{ }^{+}$. It is generally recognized that in most plants, environmental stress usually causes selective photodamage of PSII, while plants can protect PSI under environmental stress
(Kono et al. 2014). The study has found that under stressful conditions, when the electron flow from PSII to PSI exceeds the capacity of PSI electron acceptors, the acceptor side becomes overreduced. As a result, PSI is also vulnerable to damage (Suorsa et al. 2012, Tikkanen et al. 2014, Zhang et al. 2016). Millaleo et al. (2013) have found that PSI is the main target of Mn toxicity in Arabidopsis plants. They have also found that under the Mn excess, the state of $\mathrm{P} 700$ photooxidation $\left(\mathrm{P}_{700}{ }^{+}\right)$significantly decreases as compared to controls.

The decrease in CE response to environmental stress may be caused by the impaired electron transport chain. González and Lynch (2006) have reported a reduction of leaf $\mathrm{CE}$, which can be attributed to the significant decline of total Chl contents, rather than changes in stomatal conductance and transpiration rates. Chu et al. (2018) have found that in Schima superba plant, the electron transport of PSII acceptor and donor sides is blocked, and the reduction of $\mathrm{CE}$ is attributed to the inactivity of the photosynthesis rather than the stomatal limitation for the decrease in $g_{\mathrm{s}}$ but the increase in intercellular $\mathrm{CO}_{2}$ concentration $\left(C_{\mathrm{i}}\right)$. In contrast, the drought stress decreased $P_{\mathrm{N}}$ significantly for the great decline in stomatal conductance in both sun and shade plants (Valladares and Pearcy 2002). Suresh et al. (1987) have observed that excess Mn decreases stomatal conductance and transpiration rate, indicating that $\mathrm{Mn}$ is involved in stomatal regulation. Under drought stress, stomatal limitation leads to the reduction of $\mathrm{CO}_{2}$ uptake, $C_{\mathrm{i}}$, and CE of leaves (Flexas and Medrano 2002). The toxicity of heavy metals in plants depends on the type of heavy metal, the species of plant, and the concentration of heavy metals (Nagajyoti et al. 2010).

$\mathrm{Mn}$ is an essential trace element for plant metabolism and photosynthesis (Kitao et al. 1997, Li et al. 2010). However, excess Mn can decrease yield production and quality in crops (Xue et al. 2015). Mn excess is a major abiotic stress in plant agriculture worldwide (Xue et al. 2015). Melia azedarach (M. azedarach) is a preferred tree species for afforestation in industrial and mining areas, and it is also one of the tree species used for artificial afforestation in abandoned coal-skilled stone fields (Khattak and Jabeen 2012). Ligustrum lucidum (L. lucidum) has been verified to be an excellent tree species for remediation of soil ecosystems polluted by heavy metals (Tong et al. 2011). For phytoremediation, the native plants may be a better choice because they are better adapted to local climate conditions (Trikshiqi and Rexha 2015). M. azedarach and L. lucidum are common native tree species in Southern China, which are widely used in afforestation. Previous study has found that they have high tolerance in Cd-, Hg- or As-contaminated soils, showing great potential in phytoremediation of heavy metal-contaminated environments (Tong et al. 2011, Su et al. 2017). In this study, we investigated the effects of Mn stress on the photosynthetic activity and CE of $M$. azedarach and $L$. lucidum. Besides, the different states of photosynthetic system of M. azedarach and L. lucidum under excess Mn stress were also discussed. Collectively, 
our findings provided a theoretical basis for the selection of resistant tree species for the phytoremediation of Mnpolluted environments.

\section{Materials and methods}

Growth conditions and experimental design: This study was carried out in a greenhouse at Central South University of Forestry and Technology (CSUFT), Changsha City, Hunan Province of China $\left(28^{\circ} 8^{\prime} 12^{\prime \prime} \mathrm{N}, 112^{\circ} 59^{\prime} 36^{\prime \prime} \mathrm{E}\right)$. The plants were cultured at temperatures of $30 / 25^{\circ} \mathrm{C}$ and under a 12/12-h day/night cycle and maximum PAR of about $1,400 \mu \mathrm{mol}\left(\right.$ photon) $\mathrm{m}^{-2} \mathrm{~s}^{-1}$. Non-heavy metalcontaminated soil samples were collected at a depth of 5-20 cm from a garden at the CSUFT campus. Soil samples were sieved through $5 \times 5 \mathrm{~mm}$ sieves to remove large debris and rocks and then air-dried at room temperature. The chemical composition of the soil samples was as follows: $\mathrm{pH} 5.5,0.36 \mathrm{~g}(\mathrm{~N}) \mathrm{kg}^{-1}, 12.18 \mathrm{~g}(\mathrm{C}) \mathrm{kg}^{-1}$, and $463.53 \mathrm{mg}(\mathrm{Mn}) \mathrm{kg}^{-1}$.

In the present study, 2-year-old L. lucidum plants (average diameter of $9.0 \mathrm{~mm}$ and average plant height of $133.0 \mathrm{~cm}$ ) and 2-year-old M. azedarach plants (average diameter of $5.4 \mathrm{~mm}$ and average tree height of $73.3 \mathrm{~cm}$ ) were purchased from a local nursery. The plants were individually transplanted into plastic pots (diameter of $25.4 \mathrm{~cm}$ and height of $17.8 \mathrm{~cm}$ ) with one plant per pot, and each plot was filled with $5 \mathrm{~kg}$ of air-dried soil. After transplantation, the pots were maintained in the greenhouse for four months before Mn treatment. About $400 \mathrm{~mL}$ of pure water was added into each pot every $2 \mathrm{~d}$.

Three treatments with different Mn contents were set up in this study as follows: (1) soil sample $+\mathrm{Mn}$ solutions until the soil contained 4,365 $\mathrm{mg}$ of $\mathrm{Mn}$ per pot (designated as L1), (2) soil sample + Mn solutions until the soil contained 8,730 $\mathrm{mg}$ of $\mathrm{Mn}$ per pot (designated as L2), and (3) soil sample + distilled water (designated as the control). For the Mn-treated soil, distilled water containing $0.5 \mathrm{mmol}$ and $1 \mathrm{mmol}$ from $\mathrm{MnCl}_{2} \cdot 5 \mathrm{H}_{2} \mathrm{O}$ was added to the pots every other day at a rate of $400 \mathrm{~mL}$ per day for $20 \mathrm{~d}$. For the control (CK), about $400 \mathrm{~mL}$ of distilled water without $\mathrm{Mn}$ was added into the pots. Each Mn treatment was replicated five times. Thirty pots were set in this experiment including 15 pots ( 5 pots for $\mathrm{CK}$, 5 pots for L1, and 5 pots for L2) for L. lucidum and 15 pots ( 5 pots for CK, 5 pots for L1, and 5 pots for L2) for $M$. azedarach. Each pot contained one plant. All measurements were conducted on three fully expanded and similarsized leaves from each L. lucidum and M. azedarach plant and a mean value was then obtained.

Gas exchange: $P_{\mathrm{N}}, \mathrm{CE}, g_{\mathrm{s}}$, and $C_{\mathrm{i}}$ were determined by LI-COR 6400 portable photosynthesis system (LI-COR Bioscience, Lincoln, NE, USA). Under the conditions of greenhouse temperature $\left(30^{\circ} \mathrm{C}\right)$ and light intensity $[1,400$ $\mu$ mol(photon) $\mathrm{m}^{-2} \mathrm{~s}^{-1}$, concentrations of ambient $\mathrm{CO}_{2}$ $(400,350,300,250,200,150,100,50 \mathrm{ppm})$ were set to determine $P_{\mathrm{N}}$ and $C_{\mathrm{i}}$ of the same leaf, and the response curve of $P_{\mathrm{N}}-C_{\mathrm{i}}$ was drawn. The initial slope of the curve was $\mathrm{CE}, \mathrm{CE}=P_{\mathrm{N}} / C_{\mathrm{i}}$.
Chl fluorescence parameters (FPs) and JIP-test: Fast Chl $a$ fluorescence was determined by M-PEA (Multifunctional Plant Efficiency Analyzer, Hansatech Instrument, UK). The OJIP transient was induced by the red light of about $5,000 \mu \mathrm{mol}$ (photon) $\mathrm{m}^{-2} \mathrm{~s}^{-1}$, provided by an array of three light-emitting diodes (peak $650 \mathrm{~nm}$ ), recorded at 128 points and measured daily at 8:30-11:00 h. All measurements were conducted with dark-adapted plants at room temperature. The OJIP transient was analyzed by the JIP-test (Stirbet et al. 2018), which defines the flux ratios $\left[\Phi_{\mathrm{E} 0}\left(=\mathrm{ET}_{0} / \mathrm{ABS}\right), \psi_{\mathrm{E} 0}\left(=1-\mathrm{V}_{\mathrm{J}}\right), \delta_{\mathrm{R} 0}\left(=\mathrm{RE}_{0} / \mathrm{ET}_{0}\right)\right]$, performance indexes $\left[\mathrm{PI}_{\mathrm{ABS}}=\left(\mathrm{RC} / \mathrm{ABS} \times\left[\varphi_{\mathrm{P} 0} /\left(1-\varphi_{\mathrm{P} 0}\right)\right] \times\right.\right.$ $\left.\left.\left[\psi_{\mathrm{E} 0} /\left(1-\psi_{\mathrm{E} 0}\right)\right]\right)\right]$, the maximum quantum use efficiency $\left[\mathrm{F}_{\mathrm{V}} / \mathrm{F}_{\mathrm{M}}\left(=\left(\mathrm{F}_{\mathrm{M}}-\mathrm{F}_{0}\right) / \mathrm{F}_{\mathrm{M}}\right)\right]$, normalized total complementary area above the OJIP transient (reflecting single-turnover $\mathrm{Q}_{\mathrm{A}}$ reduction events) $\left[\mathrm{S}_{\mathrm{m}}\left(=\mathrm{Area} / \mathrm{F}_{\mathrm{V}}\right)\right]$, approximated initial slope of the fluorescence transient $\left[\mathrm{M}_{0}=\left(4\left[\mathrm{~F}_{300 \mu \mathrm{ss}}-\right.\right.\right.$ $\left.F_{0}\right] /\left[F_{M}-F_{0}\right]$ )], and the specific energy fluxes (per active PSII $)\left[\mathrm{ABS} / \mathrm{RC}\left(=\left[\mathrm{M}_{0} / \mathrm{V}_{\mathrm{J}}\right] / \varphi_{\mathrm{P} 0}\right), \mathrm{TR}_{0} / \mathrm{RC}\left(=\mathrm{M}_{0} / \mathrm{V}_{\mathrm{J}}\right)\right.$, $\mathrm{RE}_{0} / \mathrm{RC}\left(=\left[\mathrm{M}_{0} / \mathrm{V}_{\mathrm{J}}\right] \times \psi_{\mathrm{R} 0}\right)$, and $\mathrm{DI}_{0} / \mathrm{RC}(=\mathrm{ABS} / \mathrm{RC}-$ $\left.\left.\mathrm{TR}_{0} / \mathrm{RC}\right)\right]$.

$\mathrm{W}_{\mathrm{OK}}$ indicated the relative fluorescence between $\mathrm{O}$ and $\mathrm{K}$, while $\Delta \mathrm{W}_{\mathrm{OK}}$ indicated the difference between the $\mathrm{CK}$ groups and the treated groups:

$\mathrm{W}_{\mathrm{OK}}=\left(\mathrm{F}_{\mathrm{t}}-\mathrm{F}_{0}\right) /\left(\mathrm{F}_{\mathrm{K}}-\mathrm{F}_{0}\right)$

$\Delta \mathrm{W}_{\mathrm{OK}}=\mathrm{W}_{\mathrm{OK}}-\mathrm{W}_{\mathrm{OK}(\mathrm{control})}$

$\mathrm{V}_{\mathrm{t}}$ indicated the relative fluorescence between $\mathrm{O}$ and $\mathrm{P}$, while $\Delta \mathrm{V}_{\mathrm{t}}$ indicated the difference between the $\mathrm{CK}$ groups and the treated groups:

$\mathrm{V}_{\mathrm{t}}=\left(\mathrm{F}_{\mathrm{t}}-\mathrm{F}_{0}\right) /\left(\mathrm{F}_{\mathrm{M}}-\mathrm{F}_{0}\right)$

$\Delta \mathrm{V}_{\mathrm{t}}=\mathrm{V}_{\mathrm{t}}-\mathrm{V}_{\mathrm{t}(\text { control) }}$

IP-phase indicates the amplitude of the IP-phase or the last and slowest rate-limiting step of the photosynthetic electron transport chain (Ceppi et al. 2012).

IP-phase $=\left(F_{t}-F_{I}\right) /\left(F_{I}-F_{0}\right)$

$\mathrm{F}_{0}$ is the minimal recorded fluorescence intensity, $\mathrm{F}_{\mathrm{K}}$ and $F_{I}$ are the fluorescence intensities at K-step (300 $\left.\mu \mathrm{s}\right)$ and I-step $(30 \mathrm{~ms})$ of OJIP, respectively, and $F_{M}$ is the maximal recorded fluorescence intensity, at the peak $\mathrm{P}$ of OJIP.

The kinetics of prompt fluorescence and modulated 820-nm reflection: The red-light absorbance at a wavelength of $820 \mathrm{~nm}$ was measured by the Multifunctional Plant Efficiency Analyzer (M-PEA, Hansatech, Norfolk, UK). The $820-\mathrm{nm}$ red light absorbance was induced by a red-light pulse of about 5,000 $\mu \mathrm{mol}$ (photon) $\mathrm{m}^{-2} \mathrm{~s}^{-1}$, recorded at 128 points, and measured daily at 8:30-11:00 h. Before measuring, the leaves were dark-adapted at room temperature for $40 \mathrm{~min}$.

The oxidation of P700 and plastocyanin (PC) can increase the absorbance in the $800-850 \mathrm{~nm}$ range. After dark adaptation, most of P700 and PC were in the reduced state. Once exposed to activated light, the two photosystems were activated successively and $\mathrm{P} 700$ began to oxidize. When the absorbance of $\mathrm{P} 700$ and $\mathrm{PC}^{+}$at 
$820 \mathrm{~nm}$ increases, the $\mathrm{MR} / \mathrm{MR}_{0}$ will show a downward trend (fast phase). Subsequently, as the electrons from PSII reach P700 and PC, the oxidation rate of P700 is slowed down, and the absorbance gradually decreases, which makes the reflection absorption curve of $M R / M_{0}$ rise again, which is called the slow phase. $\Delta \mathrm{MR} / \mathrm{MR}_{0}$ was defined as the maximum reducible/oxidizable amplitude. The calculation equation is given according to Strasser et al. (2010) and Gao et al. (2014):

$\Delta \mathrm{MR} / \mathrm{MR}_{0}=\left(\mathrm{MR}_{0}-\mathrm{MR}_{\min }\right) / \mathrm{MR}_{0}$

where $\mathrm{MR}_{0}$ is the value at $0.7 \mathrm{~ms}$ and $\mathrm{MR}_{\min }$ is the lowest point in 820-nm reflection curve.

$\mathrm{V}_{\text {PSII }}=\mathrm{V}_{\text {PSI }}+\mathrm{V}_{\text {PSI }+ \text { PSII }}$

where $\mathrm{V}_{\mathrm{PSI}}$ indicates the maximum decrease in slope in the range of $0.7-3 \mathrm{~ms}$ of $\mathrm{MR} / \mathrm{MR}_{0}$ :

$\mathrm{V}_{\mathrm{PSI}}=\left(\mathrm{MR}_{0.003 \mathrm{~s}}-\mathrm{MR}_{0.0007 \mathrm{~s}}\right) /\left[\mathrm{MR}_{0} \times\left(\mathrm{t}_{0.003 \mathrm{~s}}-\mathrm{t}_{0.0007 \mathrm{~s}}\right)\right]$

and $\mathrm{V}_{\mathrm{PSI}+\mathrm{VPSI}}$ indicates the maximum increase in slope in the range of $7-300 \mathrm{~ms}$ of $\mathrm{MR} / \mathrm{MR}_{0}$ :

$\mathrm{V}_{\text {PSI+VPSII }}=\left(\mathrm{MR}_{0.3 \mathrm{~s}}-\mathrm{MR}_{0.007 \mathrm{~s}}\right) /\left[\mathrm{MR}_{0} \times\left(\mathrm{t}_{0.3 \mathrm{~s}}-\mathrm{t}_{0.007 \mathrm{~s}}\right)\right]$

Total Mn content and translation factor: The different organs (roots, stems, and leaves) of the harvested $L$. lucidum and $M$. azedarach were washed with pure water. The plant materials were kept at $105^{\circ} \mathrm{C}$ for killing out and then dried at $75^{\circ} \mathrm{C}$ for $48 \mathrm{~h}$. The different organs were powdered and used to determine the Mn contents of different organs by ICP-AES (Optima 8300, American Platinum Elmer, USA) after digestion with $\mathrm{HNO}_{3}-\mathrm{HClO}_{4}$ (Han et al. 2016). Translation factor $=$ Mn content in the leaves/Mn content in the roots.

Data analysis: Data were expressed as the mean value of each group consisting of three independent replicates. Results were presented as means \pm standard error (SE). Statistical differences between measurements were analyzed using one-way analysis of variance (ANOVA), followed by the least significant difference (LSD) test by SPSS 21. Pearson's correlation analysis was used to address the relationships between $\mathrm{Mn}$ contents and photosynthetic parameters in leaves on day 30 in $M$. azedarach and L. lucidum. All graphs were made by Origin 9.1. A $p<0.05$ was considered statistically significant.

\section{Results}

The contents of $\mathrm{Mn}$ in roots, stems, and leaves: The total Mn content in the Mn-treated M. azedarach and L. lucidum roots, stems, and leaves on day 30 was significantly increased compared to that of the control groups, and such elevation corresponded to the increasing Mn treatment. This increasing trend was observed under all treatment groups in all components of both tree species, except for the roots in the L1-treated group compared to that of the L2-treated group of M. azedarach. The Mn concentrations were the highest in the roots, followed by that of the leaves and stems (Fig. 1).
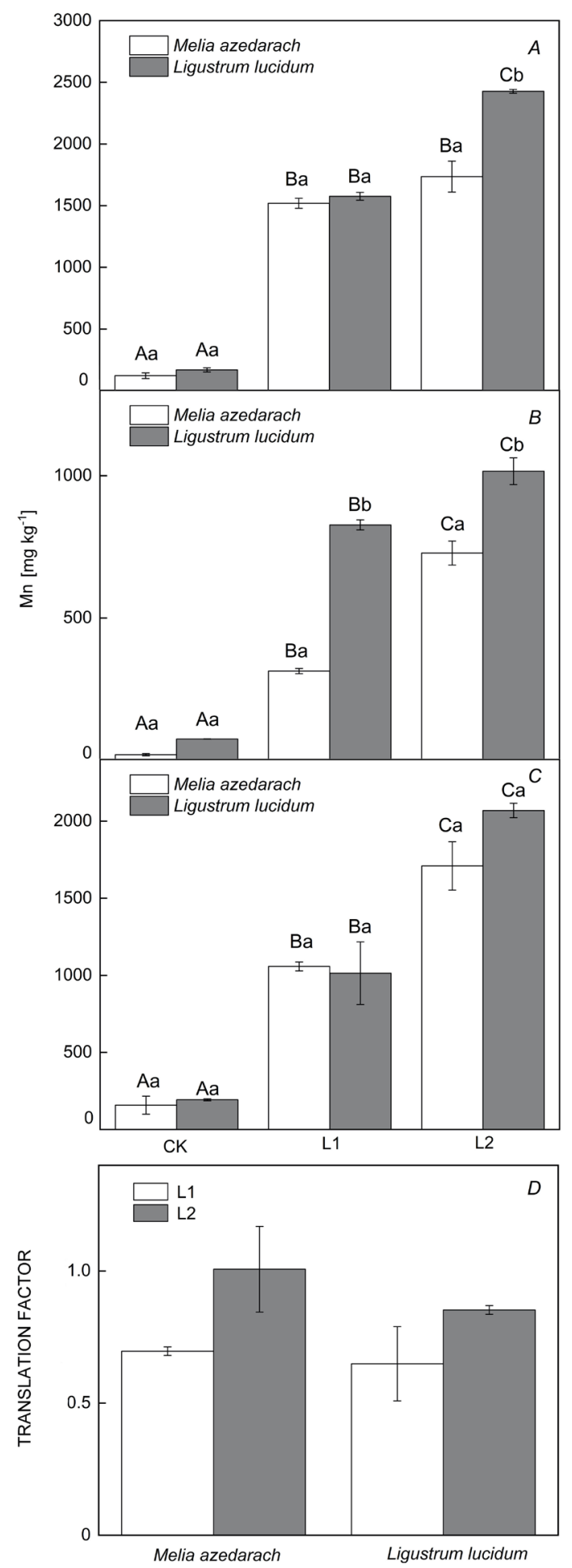

Fig. 1. The contents of $\mathrm{Mn}$ in roots $(A)$, stems $(B)$, and leaves $(C)$ and the translocation factor $(D)$ of Melia azedarach and Ligustrum lucidum in the Mn-treated groups on day 30. L1 - $0.5 \mathrm{mmol} \mathrm{Mn}$ treatment; $\mathrm{L} 2-1 \mathrm{mmol} \mathrm{Mn}$ treatment. The data represent mean \pm SE, $n=5$. Different capital letters represent significant difference between different Mn treatments in the same organ of plant and the same tree species $(p<0.05)$. Different lowercase letters represent significant difference between different tree species in the same organ of plant and the same Mn treatment $(p<0.05)$ 
The Mn content in the stems of L. lucidum under $\mathrm{Mn}$ treatments was significantly higher compared to $M$. azedarach in L1 and L2 treatment. There was no significant difference in the roots and leaves of L. lucidum and $M$. azedarach in all Mn-treated groups, except for that in the roots of the L2-treated group (Fig. 1).

The translation factors of both tree species increased with the increase of $\mathrm{Mn}$ concentration. The increased amplitude of the translation factor in $M$. azedarach was higher than that of L. lucidum.

Gas exchange: Mn stress decreased the $P_{\mathrm{N}}, g_{\mathrm{s}}$, and CE but increased the $C_{\mathrm{i}}$ for both tested tree species compared with controls (Table 1). For $g_{\mathrm{s}}$ and $C_{\mathrm{i}}$, there was no significant difference between the $\mathrm{Mn}$ treatment groups and the control for both tested tree species (Table 1). $P_{\mathrm{N}}$ and CE significantly decreased in L2-treated groups compared with those of the control in both tree species, and there was no significant difference between the L1-treated groups and the control in both tree species (Table 1).

\section{OJIP curve and light-induced modulated 820-nm} reflection $\left(\mathbf{M R} / \mathbf{M R}_{\mathbf{0}}\right)$ kinetics: All OJIP transients from the leaves of the Mn-treated groups and the controls showed a typical polyphasic rise, and the basic process was OJIP. The values of $F_{0}$ showed a gradual increase in response to $\mathrm{Mn}$ treatment of $M$. azedarach and L. lucidum (Fig. 2A,F). The fluorescence induction curve of $M$. azedarach and $L$. lucidum did not show a considerable change in response to Mn excess on day 10. However, M. azedarach and L. lucidum exhibited a prominent rise of fluorescence intensity at L, K, J, and I points of the transient curve in response to Mn excess on day 30. In L2-treated groups on day 30, the increases of $\mathrm{L}, \mathrm{K}, \mathrm{J}$, and I were higher in $M$. azedarach compared to L. lucidum (Fig. 2B,C,G,H). The maximum amplitude of the IP-phase progressively decreased with the increase of Mn concentration and the treatment time for both tested tree species. $M$. azedarach showed a faster decrease in the IP-phase compared to L. lucidum (Fig. 2D,l).

Under $\mathrm{Mn}$ stress, $\mathrm{MR} / \mathrm{MR}_{0}$ kinetics were changed in both tree species. As shown in Fig. 2, the rate of fast decline of the $\mathrm{MR} / \mathrm{MR}_{0}$ curve changed from 10 to $30 \mathrm{~d}$ of $\mathrm{Mn}$ stress. $\mathrm{MR}_{\min }$ increased and the time to reach the $\mathrm{MR}_{\min }$ shifted forward. $\mathrm{V}_{\mathrm{PSI}}$ decreased but not significantly in response to $\mathrm{Mn}$ treatment of L. lucidum on 10 and
$30 \mathrm{~d}$ (Table 2). The $\mathrm{V}_{\mathrm{PSI}}$ of $M$. azedarach decreased but not significantly on day 10 but decreased significantly in the L1- and L2-treated groups compared with that of the controls (Table 2). For the slow rising phase of MR/MR the $\mathrm{V}_{\mathrm{PSI}+\mathrm{PSII}}$ decreased but not significantly in response to Mn treatment of L. lucidum on 10 and $30 \mathrm{~d}$ (Table 2). $\mathrm{V}_{\mathrm{PSI}+\mathrm{PSII}}$ of $M$. azedarach decreased but not significantly on day 10 but decreased significantly in the L1- and L2-treated groups compared with that of the controls. $\mathrm{V}_{\mathrm{PSII}}$ decreased but not significantly in response to $\mathrm{Mn}$ treatment of L. lucidum on 10 and $30 \mathrm{~d}$. $\mathrm{V}_{\mathrm{PSII}}$ of $M$. azedarach decreased but not significantly on day 10 but decreased significantly in the L1- and L2-treated groups compared with that of the controls (Fig. 2E,J; Table 2).

Quantum efficiency and FPs: On day $10, \mathrm{PI}_{\mathrm{ABS}}, \mathrm{F}_{\mathrm{V}} / \mathrm{F}_{\mathrm{M}}$, $\mathrm{S}_{\mathrm{m}}, \Phi_{\mathrm{E} 0}, \psi_{\mathrm{E} 0}$, and $\delta_{\mathrm{R} 0}$ decreased but not significantly in L1and L2-treated groups compared with those of the controls (Fig. 3). $\mathrm{M}_{0}$ and $\mathrm{W}_{\mathrm{K}}$ increased but not significantly for both tree species in L1- and L2-treated groups compared with those of the controls (Fig. $3 B, D$ ). The $\mathrm{W}_{\mathrm{K}}$ in L. lucidum in L2-treated groups significantly increased compared with that of the controls (Fig. 3D).

For $M$. azedarach, $\mathrm{W}_{\mathrm{K}}$ in L2-treated groups and $\mathrm{M}_{0}$ in L1 and L2 treatment groups significantly increased compared with those of the controls, while $\mathrm{PI}_{\mathrm{ABS}}, \mathrm{F}_{\mathrm{V}} / \mathrm{F}_{\mathrm{M}}$, and $\Phi_{\mathrm{E} 0}$ in L2 treatment groups significantly decreased compared with those of the controls on day 30 (Fig. 3). $\mathrm{PI}_{\mathrm{ABS}}$ and $\mathrm{F}_{\mathrm{V}} / \mathrm{F}_{\mathrm{M}}$ in $\mathrm{L} 1$ treatment groups significantly decreased compared with those of the controls on day 30 (Fig. $3 A, E) . \mathrm{S}_{\mathrm{m}}, \delta_{\mathrm{R} 0}$, and $\psi_{\mathrm{E} 0}$ decreased but not significantly compared with those of the controls in L1 and L2 treatment groups on day 30 (Fig. $3 C, F, H$ ).

For L. lucidum, $\mathrm{W}_{\mathrm{K}}$ and $\mathrm{M}_{0}$ in $\mathrm{L} 2$ treatment groups significantly increased compared with those of the controls, while $\mathrm{PI}_{\mathrm{ABS}}, \mathrm{F}_{\mathrm{V}} / \mathrm{F}_{\mathrm{M}}$, and $\mathrm{S}_{\mathrm{m}}$ in $\mathrm{L} 2$ treatment groups significantly decreased compared with those of the controls on day $30 . \Phi_{\mathrm{E} 0}, \delta_{\mathrm{R} 0}$, and $\psi_{\mathrm{E} 0}$ decreased but not significantly compared with those of the controls in L1 and L2 treatment groups on day 30 (Fig. 3).

Effect of special energy fluxes or activities per reaction center: Mn stress increased but not significantly ABS/RC, $\mathrm{TR}_{0} / \mathrm{RC}$, and $\mathrm{DI}_{0} / \mathrm{RC}$ on day 10 but decreased $\mathrm{RE}_{0} / \mathrm{RC}$ in $M$. azedarach. The $\mathrm{ABS} / \mathrm{RC}, \mathrm{TR}_{0} / \mathrm{RC}$, and $\mathrm{DI}_{0} / \mathrm{RC}$ increased significantly compared with those of the

Table 1. Changes in net photosynthetic rate $\left(P_{\mathrm{N}}\right)$, stomatal conductance $\left(g_{\mathrm{s}}\right)$, intercellular $\mathrm{CO}_{2}$ concentration $\left(C_{\mathrm{i}}\right)$, and carboxylation efficiency (CE) in the control and Mn-treated groups on day 30 in Melia azedarach and Ligustrum lucidum. The data represent mean $\pm \mathrm{SE}(n=5)$ and values followed by different capital letters represent significant difference between Mn treatments in the same tree species $(p<0.05)$. CK - control; L1 - $0.5 \mathrm{mmol} \mathrm{Mn}$ treatment; L2 - $1 \mathrm{mmol} \mathrm{Mn} \mathrm{treatment.}$

\begin{tabular}{|c|c|c|c|c|c|c|}
\hline & \multicolumn{3}{|l|}{ Melia azedarach } & \multicolumn{3}{|c|}{ Ligustrum lucidum } \\
\hline & $\mathrm{CK}$ & L1 & L2 & $\mathrm{CK}$ & $\mathrm{L} 1$ & L2 \\
\hline$P_{\mathrm{N}}\left[\mu \mathrm{mol} \mathrm{m}{ }^{-2} \mathrm{~s}^{-1}\right]$ & $5.61 \pm 0.58^{\mathrm{A}}$ & $4.83 \pm 0.23^{\mathrm{AB}}$ & $3.52 \pm 0.44^{\mathrm{B}}$ & $5.46 \pm 0.23^{\mathrm{A}}$ & $5.16 \pm 0.41^{\mathrm{AB}}$ & $4.02 \pm 0.48^{\mathrm{B}}$ \\
\hline$g_{\mathrm{s}}\left[\mathrm{mol} \mathrm{m}^{-2} \mathrm{~s}^{-1}\right]$ & $0.057 \pm 0.008^{\mathrm{A}}$ & $0.045 \pm 0.004^{\mathrm{A}}$ & $0.035 \pm 0.001^{\mathrm{A}}$ & $0.033 \pm 0.001^{\mathrm{A}}$ & $0.033 \pm 0.002^{\mathrm{A}}$ & $0.031 \pm 0.007^{\mathrm{A}}$ \\
\hline$C_{\mathrm{i}}\left[\mu \mathrm{mol} \mathrm{\textrm {mol } ^ { - 1 } ]}\right.$ & $213.94 \pm 16.23^{\mathrm{A}}$ & $203.63 \pm 7.93^{\mathrm{A}}$ & $211.00 \pm 14.15^{\mathrm{A}}$ & $119.87 \pm 2.76^{\mathrm{A}}$ & $121.27 \pm 16.87^{\mathrm{A}}$ & $158.84 \pm 18.28^{\mathrm{A}}$ \\
\hline $\mathrm{CE}\left[\mathrm{mol} \mathrm{m}{ }^{-2} \mathrm{~s}^{-1}\right]$ & $0.051 \pm 0.005^{\mathrm{A}}$ & $0.030 \pm 0.002^{\mathrm{AB}}$ & $0.023 \pm 0.003^{\mathrm{B}}$ & $0.078 \pm 0.002^{\mathrm{A}}$ & $0.050 \pm 0.002^{\mathrm{AB}}$ & $0.033 \pm 0.002^{\mathrm{B}}$ \\
\hline
\end{tabular}



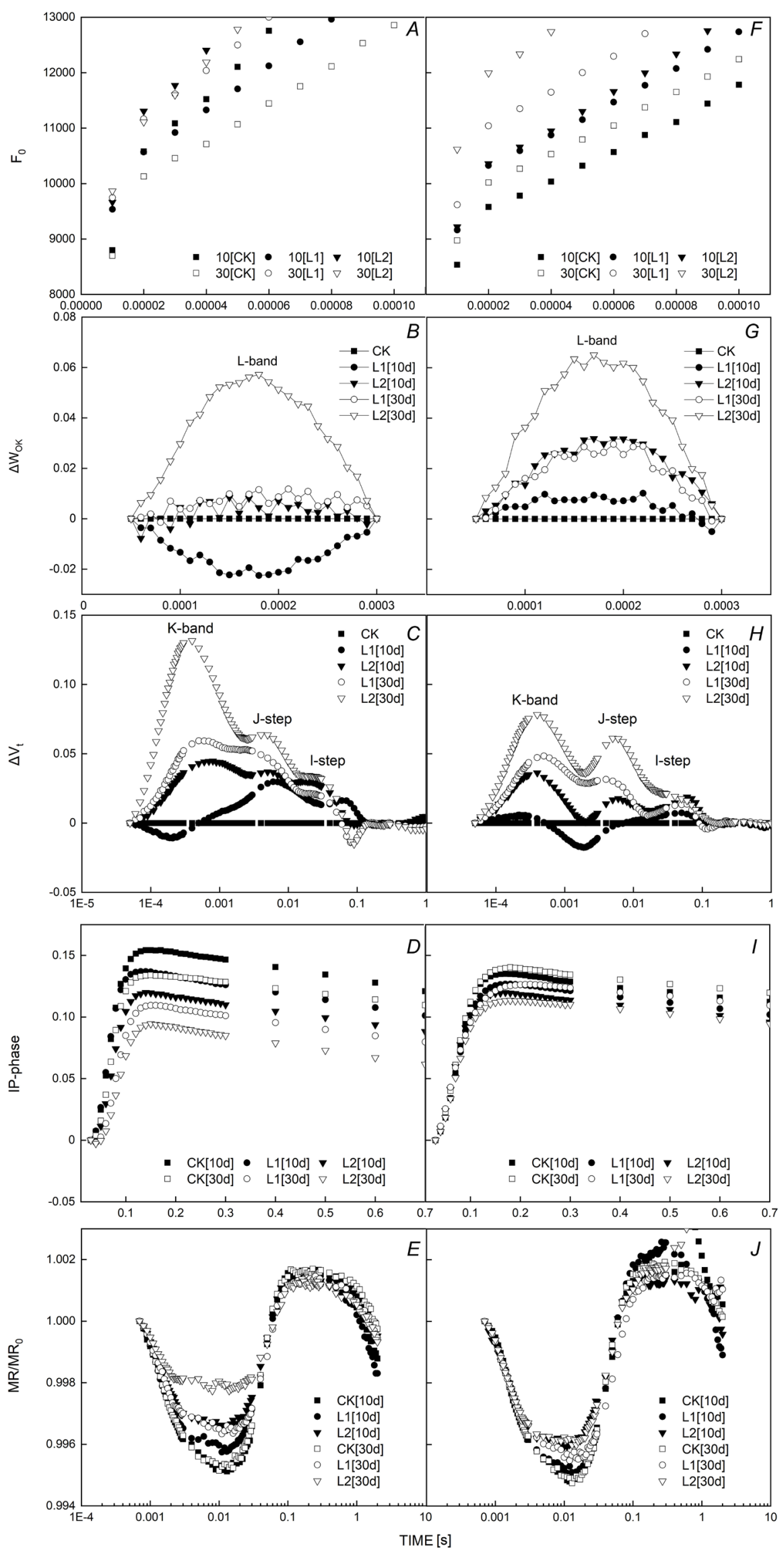

Fig. 2. Effects of excess $\mathrm{Mn}$ on the different expressions of relative variable fluorescence derived from the average OJIP transient and the kinetics of prompt fluorescence and modulated $820-\mathrm{nm}$ reflection of Melia azedarach $(A-E)$ and Ligustrum lucidum $(F-J)$ on day 10 and day 30. CK - control; L1 $0.5 \mathrm{mmol} \mathrm{Mn}$ treatment; $\mathrm{L} 2-1 \mathrm{mmol}$ Mn treatment. $\mathrm{F}_{0}$ - minimal recorded fluorescence intensity; $\Delta \mathrm{W}_{\mathrm{OK}}$ the difference between the CK groups and the treated groups in the relative fluorescence between $\mathrm{O}$ and $\mathrm{K}$; $\Delta \mathrm{V}_{\mathrm{t}}$ - the difference between the CK groups and the treated groups in the relative fluorescence between $\mathrm{O}$ and P; IP-phase - the amplitude of the IP-phase; MR/MR - the maximum reducible/oxidizable amplitude. 
Table 2. The parameters of the kinetics of prompt fluorescence and modulated 820-nm reflection on day10 and 30 in Melia azedarach and Ligustrum lucidum. The data represent mean \pm SE $(n=5)$ and values followed by different capital letters represent significant difference between different $\mathrm{Mn}$ treatments in the same tree species and stress time $(p<0.05)$. $\mathrm{V}_{\mathrm{PSI}}-$ maximum decrease in slope in the range of $0.7-3 \mathrm{~ms}$ of $\mathrm{MR} / \mathrm{MR}_{0} ; \mathrm{V}_{\mathrm{PSI}+\mathrm{PSII}}$ - maximum increase in slope in the range of 7-300 $\mathrm{ms}$ of $\mathrm{MR} / \mathrm{MR}_{0}$; $\mathrm{V}_{\mathrm{PSII}}-$ the PSII activity.

\begin{tabular}{|c|c|c|c|c|c|c|}
\hline & \multicolumn{3}{|l|}{ Melia azedarach } & \multicolumn{3}{|c|}{ Ligustrum lucidum } \\
\hline & $\mathrm{CK}$ & L1 & L2 & $\mathrm{CK}$ & L1 & L2 \\
\hline \multicolumn{7}{|c|}{ Mn-stress for 10 days } \\
\hline $\mathrm{V}_{\mathrm{PSI}}$ & $1.672 \pm 0.211^{\mathrm{A}}$ & $1.511 \pm 0.003^{\mathrm{A}}$ & $1.301 \pm 0.213^{\mathrm{A}}$ & $1.676 \pm 0.117^{\mathrm{A}}$ & $1.630 \pm 0.001^{\mathrm{A}}$ & $1.475 \pm 0.119^{\mathrm{A}}$ \\
\hline $\mathrm{V}_{\text {PSI+PSII }}$ & $0.021 \pm 0.035^{\mathrm{A}}$ & $0.019 \pm 0.000^{\mathrm{A}}$ & $0.017 \pm 0.035^{\mathrm{A}}$ & $0.022 \pm 0.147^{\mathrm{A}}$ & $0.024 \pm 0.003^{\mathrm{A}}$ & $0.018 \pm 0.150^{\mathrm{A}}$ \\
\hline $\mathrm{V}_{\mathrm{PSII}}$ & $1.693 \pm 0.052^{\mathrm{A}}$ & $1.530 \pm 0.002^{\mathrm{A}}$ & $1.318 \pm 0.054^{\mathrm{A}}$ & $1.698 \pm 0.160^{\mathrm{A}}$ & $1.655 \pm 0.001^{\mathrm{A}}$ & $1.493 \pm 0.161^{\mathrm{A}}$ \\
\hline \multicolumn{7}{|c|}{ Mn-stress for 30 days } \\
\hline $\mathrm{V}_{\mathrm{PSI}}$ & $1.618 \pm 0.152^{\mathrm{A}}$ & $1.301 \pm 0.001^{\mathrm{B}}$ & $0.806 \pm 0.154^{\mathrm{B}}$ & $1.619 \pm 0.042^{\mathrm{A}}$ & $1.458 \pm 0.001^{\mathrm{A}}$ & $1.434 \pm 0.043^{\mathrm{A}}$ \\
\hline $\mathrm{V}_{\text {PSI+PSII }}$ & $0.021 \pm 0.109^{\mathrm{A}}$ & $0.016 \pm 0.001^{\mathrm{B}}$ & $0.011 \pm 0.110^{\mathrm{C}}$ & $0.023 \pm 0.085^{\mathrm{A}}$ & $0.019 \pm 0.002^{\mathrm{A}}$ & $0.019 \pm 0.087^{\mathrm{A}}$ \\
\hline $\mathrm{V}_{\mathrm{PSII}}$ & $1.639 \pm 0.100^{\mathrm{A}}$ & $1.317 \pm 0.001^{\mathrm{B}}$ & $0.817 \pm 0.101^{\mathrm{B}}$ & $1.642 \pm 0.199^{\mathrm{A}}$ & $1.477 \pm 0.002^{\mathrm{A}}$ & $1.453 \pm 0.200^{\mathrm{A}}$ \\
\hline
\end{tabular}

controls, but the $\mathrm{RE}_{0} / \mathrm{RC}$ increased in the $\mathrm{L} 2$ treatment group compared with the controls of L. lucidum on day 10 (Table 3).

$\mathrm{Mn}$ stress significantly increased $\mathrm{TR}_{0} / \mathrm{RC}, \mathrm{ABS} / \mathrm{RC}$, and $\mathrm{DI}_{0} / \mathrm{RC}$ in the $\mathrm{L} 2$ treatment groups compared with those of the controls for M. azedarach and L. lucidum on day $30 . \mathrm{RE}_{0} / \mathrm{RC}$ increased but not significantly in the L1 and L 2 treatment groups compared with that of the controls for L. lucidum but decreased but not significantly in the L1 and L2 treatment groups of M. azedarach (Table 3).

Correlation analysis: In L. lucidum, Pearson's correlation analysis showed that $\mathrm{PI}_{\mathrm{ABS}}$ was significantly positively correlated to $\Phi_{\mathrm{E} 0}$ and CE. The Mn concentration in leaves was significantly negatively correlated to $\mathrm{PI}_{\mathrm{ABS}}$. The $\mathrm{Mn}$ concentration in leaves was significantly negatively correlated to $\Phi_{\mathrm{E} 0}$. There were no significant relationships between $\mathrm{CE}$ and $\mathrm{V}_{\mathrm{PSI}}, \mathrm{CE}$ and $\mathrm{V}_{\mathrm{PSII}}$ (Table 4).

In $M$. azedarach, Pearson's correlation analysis showed that $\mathrm{PI}_{\mathrm{ABS}}$ was significantly positively correlated to $\Phi_{\mathrm{E} 0}$ and CE. $\Phi_{\mathrm{E} 0}$ was significantly positively correlated to CE. $V_{\text {PSI }}$ and $V_{\text {PSII }}$ were significantly positively correlated to $\mathrm{CE}$. The $\mathrm{Mn}$ concentration in leaves was significantly negatively correlated to $\mathrm{PI}_{\mathrm{ABS}}, \Phi_{\mathrm{E} 0}, \mathrm{~V}_{\mathrm{PSI}}$, and $\mathrm{V}_{\mathrm{PSII}}$ (Table 4).

\section{Discussion}

Mn-induced decrease of the PSII activity: It is well known that the functions of PSII (donor and acceptor sides) and the electron-transfer chain might be damaged by the toxicity of heavy metals (Belatik et al. 2013, Li and Zhang 2015, Lin and Jin 2018). The Chl fluorescence transient (OJIP transient) can be used as a tool to assess photosynthesis (Kalaji and Loboda 2007). The O-J reflects the state of the reduction of the acceptor side of PSII. The Mn-induced K-step in the OKJIP at $300 \mu$ s was consistent with the results obtained from wheat under Mn stress (Fig. 2C,H) (Macfie and Taylor 1992). The increase in $\mathrm{W}_{\mathrm{K}}$ might be related to an inactivation of the oxygen-evolving complex (OEC) (Strasser 1997, Stirbet et al. 2014, Chang et al. 2017), and the OEC splits water molecules to provide electrons to PSII reaction centers. Schmidt et al. (2016) found that the positive K-band can be observed in the seeds of two barley genotypes under Mn deficiency for a damaged and dysfunctional OEC. The same phenomenon was observed in our study. With the increase in $\mathrm{Mn}$ content and duration of stress, $\mathrm{W}_{\mathrm{K}}$ gradually increased and reached the maximum in L2 groups on day 30. These results indicate the photodamage to the OEC that leads to a disturbance of electron transfer from the donor side to the acceptor side of PSII (Fig. 2). The K-band in $M$. azedarach was higher than that in L. lucidum, indicating that the OEC in $M$. azedarach is more vulnerable to $\mathrm{Mn}$ toxicity. The J-step represents the redox state of the first electron acceptor of PSII $\left(\mathrm{Q}_{\mathrm{A}}\right)$ and the accumulation of $\mathrm{Q}_{\mathrm{A}}$ (Mehta et al. 2010). The relative fluorescence intensity $\left(\Delta V_{t}\right)$ of the J-step was higher in Mn-treated groups in both trees compared with that of the controls, indicating that the electron transfer chain of PSII was inhibited, leading to the accumulation of $\mathrm{Q}_{\mathrm{A}^{-}}$(Jiang et al. 2008, Mlinarić et al. 2017). The J-I phase represents the change of the PQ pool (Fig. 2C,H). The relative fluorescence intensity $\left(\Delta V_{t}\right)$ of the I-step was higher in Mn-treated groups in both trees compared with that of the controls, indicating the accumulation of $\mathrm{Q}_{\mathrm{A}}{ }^{-} \mathrm{Q}_{\mathrm{B}}{ }^{-}$(Gomes et al. 2012). In the present study, we found that electron transport downstream of $\mathrm{Q}_{\mathrm{A}}$ was significantly reduced by $\mathrm{Mn}$ stress in both trees. This result is supported by the significant increase in $\mathrm{M}_{0}$ and the significant decrease in $\mathrm{S}_{\mathrm{m}}$ (Fig. $3 B, F$ ). When the electron transport downstream of $\mathrm{Q}_{\mathrm{A}}$ was inhibited by DCMU (Strasser et al. 1995), the $\mathrm{M}_{0}$ increased. $\mathrm{S}_{\mathrm{m}}$ reflects the size of the PQ pool on the receptor side of the PSII reaction center and the energy required to completely reduce $\mathrm{Q}_{\mathrm{A}}$. The more electrons that enter the electron transfer chain from $\mathrm{Q}_{\mathrm{A}}^{-}$, the longer it takes to reach $\mathrm{F}_{\mathrm{M}}$, the greater the value of $S_{m}$. But in the present study, the $S_{m}$ and $F_{M}$ (Figs. 2D,I;3F) decreased significantly in L2 groups on day 30, suggesting that Mn excess decreased the size of the PQ pool and inhibited the acceptor of PSII. These results were supported by the decreased value of $\psi_{\mathrm{E} 0}$ and $\Phi_{\mathrm{E} 0}$ (Fig. 3C, $)$, leading to an inhibition in the acceptor side of PSII. 


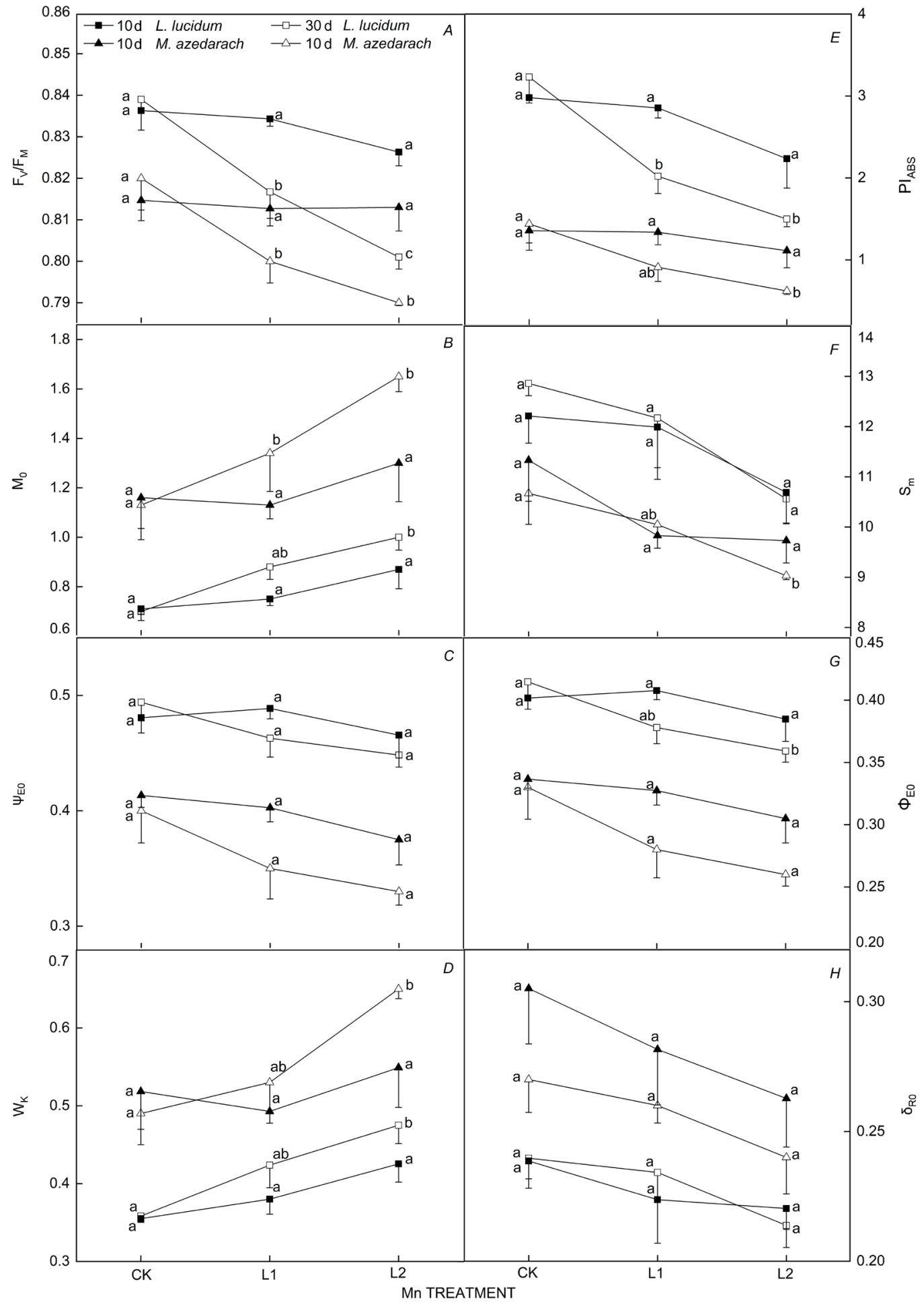

Fig. 3. Changes of yields or flux ratios $\left(\psi_{\mathrm{E} 0}, \delta_{\mathrm{R} 0}\right), \mathrm{PI}_{\mathrm{ABS}}, \mathrm{W}_{\mathrm{K}}, \mathrm{S}_{\mathrm{m}}, \psi_{\mathrm{E} 0}, \Phi_{\mathrm{E} 0}$, and $\mathrm{F}_{\mathrm{V}} / \mathrm{F}_{\mathrm{M}}$ in the control and Mn-treated groups on day 10 and 30 in Ligustrum lucidum and Melia azedarach. CK - control; L1 - $0.5 \mathrm{mmol} \mathrm{Mn} \mathrm{treatment;} \mathrm{L2} \mathrm{-} 1 \mathrm{mmol} \mathrm{Mn}$ treatment. The data represent mean $\pm \mathrm{SE}(n=5)$ and values followed by different lowercase letters represent significant difference between different Mn treatments in the same tree species and stress time $(p<0.05) . \mathrm{F}_{\mathrm{V}} / \mathrm{F}_{\mathrm{M}}-$ maximum quantum use efficiency; $\mathrm{M}_{0}$ - approximated initial slope of the fluorescence transient; $\psi_{\mathrm{E} 0}$ - probability that a trapped exciton moves an electron into the electron transport chain beyond $\mathrm{Q}_{\mathrm{A}} ; \mathrm{W}_{\mathrm{K}}-$ relative variable fluorescence at the K-step to the amplitude $\mathrm{F}_{\mathrm{J}}-\mathrm{F}_{0} ; \mathrm{PI}_{\mathrm{ABS}}$ - performance index; $\mathrm{S}_{\mathrm{m}}$ - normalized total complementary area above the OJIP transient (reflecting single-turnover $\mathrm{Q}_{\mathrm{A}}$ reduction events); $\Phi_{\mathrm{E} 0}-$ quantum yield for electron transport; $\delta_{\mathrm{R} 0}-$ efficiency with which an electron can move from the reduced intersystem electron acceptors to the PSI end electron acceptors. 
Table 3. Mn effect on the special energy fluxes or activities per reaction center on day10 and 30 in Melia azedarach and Ligustrum lucidum. The data represent mean $\pm \mathrm{SE}(n=5)$ and values followed by different capital letters represent significant difference between different $\mathrm{Mn}$ treatments in the same tree species and stress time $(p<0.05)$. ABS/RC - absorption flux (of antenna Chls) per RC (also a measure of PSII apparent antenna size); $\mathrm{TR}_{0} / \mathrm{RC}$ - trapped energy flux (leading to $\mathrm{Q}_{\mathrm{A}}$ reduction) per $\mathrm{RC}$ at $\mathrm{t}=0 ; \mathrm{RE}_{0} / \mathrm{RC}-\mathrm{the}$ flux of electrons transferred from $\mathrm{Q}_{\mathrm{A}}^{-}$to final PSI acceptors per PSII at $\mathrm{t}=0 ; \mathrm{DI}_{0} / \mathrm{RC}-$ dissipated energy flux per $\mathrm{RC}$ at $\mathrm{t}=0$.

\begin{tabular}{|c|c|c|c|c|c|c|}
\hline & \multicolumn{3}{|c|}{ Melia azedarach } & \multicolumn{3}{|c|}{ Ligustrum lucidum } \\
\hline & $\mathrm{CK}$ & L1 & L2 & $\mathrm{CK}$ & L1 & L2 \\
\hline \multicolumn{7}{|c|}{ Mn-stress for 10 days } \\
\hline $\mathrm{ABS} / \mathrm{RC}$ & $2.32 \pm 0.19^{\mathrm{A}}$ & $2.22 \pm 0.07^{\mathrm{A}}$ & $2.46 \pm 0.23^{\mathrm{A}}$ & $1.58 \pm 0.00^{\mathrm{A}}$ & $1.69 \pm 0.08^{\mathrm{AB}}$ & $1.91 \pm 0.11^{\mathrm{B}}$ \\
\hline $\mathrm{TR}_{0} / \mathrm{RC}$ & $1.89 \pm 0.16^{\mathrm{A}}$ & $1.81 \pm 0.05^{\mathrm{A}}$ & $1.99 \pm 0.17^{\mathrm{A}}$ & $1.32 \pm 0.01^{\mathrm{A}}$ & $1.41 \pm 0.07^{\mathrm{AB}}$ & $1.58 \pm 0.08^{\mathrm{B}}$ \\
\hline $\mathrm{RE}_{0} / \mathrm{RC}$ & $0.24 \pm 0.03^{\mathrm{A}}$ & $0.20 \pm 0.02^{\mathrm{A}}$ & $0.20 \pm 0.02^{\mathrm{A}}$ & $0.15 \pm 0.01^{\mathrm{A}}$ & $0.15 \pm 0.01^{\mathrm{A}}$ & $0.16 \pm 0.01^{\mathrm{A}}$ \\
\hline $\mathrm{DI}_{0} / \mathrm{RC}$ & $0.43 \pm 0.03^{\mathrm{A}}$ & $0.42 \pm 0.02^{\mathrm{A}}$ & $0.46 \pm 0.06^{\mathrm{A}}$ & $0.26 \pm 0.01^{\mathrm{A}}$ & $0.28 \pm 0.02^{\mathrm{AB}}$ & $0.33 \pm 0.02^{\mathrm{B}}$ \\
\hline \multicolumn{7}{|c|}{ Mn-stress for 30 days } \\
\hline $\mathrm{ABS} / \mathrm{RC}$ & $2.21 \pm 0.19^{\mathrm{A}}$ & $2.44 \pm 0.19^{\mathrm{AB}}$ & $2.96 \pm 0.05^{\mathrm{B}}$ & $1.59 \pm 0.04^{\mathrm{A}}$ & $1.93 \pm 0.15^{\mathrm{AB}}$ & $2.19 \pm 0.09^{\mathrm{B}}$ \\
\hline $\mathrm{TR}_{0} / \mathrm{RC}$ & $1.80 \pm 0.14^{\mathrm{A}}$ & $1.94 \pm 0.13^{\mathrm{AB}}$ & $2.33 \pm 0.04^{\mathrm{B}}$ & $1.34 \pm 0.03^{\mathrm{A}}$ & $1.58 \pm 0.11^{\mathrm{AB}}$ & $1.76 \pm 0.08^{\mathrm{B}}$ \\
\hline $\mathrm{RE}_{0} / \mathrm{RC}$ & $0.20 \pm 0.01^{\mathrm{A}}$ & $0.18 \pm 0.00^{\mathrm{A}}$ & $0.18 \pm 0.01^{\mathrm{A}}$ & $0.16 \pm 0.01^{\mathrm{A}}$ & $0.17 \pm 0.02^{\mathrm{A}}$ & $0.17 \pm 0.01^{\mathrm{A}}$ \\
\hline $\mathrm{DI}_{0} / \mathrm{RC}$ & $0.41 \pm 0.05^{\mathrm{A}}$ & $0.50 \pm 0.05^{\mathrm{AB}}$ & $0.63 \pm 0.01^{\mathrm{B}}$ & $0.26 \pm 0.01^{\mathrm{A}}$ & $0.36 \pm 0.04^{\mathrm{B}}$ & $0.44 \pm 0.01^{\mathrm{B}}$ \\
\hline
\end{tabular}

Table 4. Pearson's correlation coefficients between Mn concentration, $\mathrm{CO}_{2}$ fixation, and photosynthesis parameters in leaves on day 30 in Melia azedarach and Ligustrum lucidum. ${ }^{*}$ Correlation is significant at the 0.05 level $(p<0.05)$. ${ }^{* *}$ Correlation is significant at the 0.01 level $(p<0.01)$. CE - carboxylation efficiency; $\mathrm{PI}_{\mathrm{ABS}}$ - performance index; $\mathrm{V}_{\mathrm{PSI}}-$ maximum decrease in slope in the range of $0.7-3 \mathrm{~ms}$ of $\mathrm{MR} / \mathrm{MR}_{0} ; \mathrm{V}_{\mathrm{PSII}}$ - the activity of PSII; $\Phi_{\mathrm{E} 0}$ - quantum yield for electron transport; $\mathrm{Mn}$ - the Mn concentration in leaves.

\begin{tabular}{lccccccrr}
\hline & \multicolumn{7}{c}{ Melia azedarach } & \multicolumn{2}{c}{ Ligustrum lucidum } \\
& $\mathrm{PI}_{\mathrm{ABS}}$ & $\Phi_{\mathrm{E} 0}$ & \multicolumn{1}{c}{$\mathrm{V}_{\mathrm{PSI}}$} & \multicolumn{1}{c}{$\mathrm{V}_{\mathrm{PSII}}$} & \multicolumn{1}{c}{$\mathrm{PI}_{\mathrm{ABS}}$} & \multicolumn{1}{c}{$\Phi_{\mathrm{E} 0}$} & \multicolumn{1}{c}{$\mathrm{V}_{\mathrm{PSI}}$} & \multicolumn{1}{c}{$\mathrm{V}_{\mathrm{PSII}}$} \\
\hline $\mathrm{CE}$ & $0.877^{* *}$ & $0.779^{*}$ & $0.891^{* *}$ & $0.891^{* *}$ & $0.717^{*}$ & 0.447 & 0.525 & 0.529 \\
$\mathrm{Mn}$ & $-0.771^{*}$ & $-0.731^{*}$ & $-0.852^{* *}$ & $-0.853^{* *}$ & $-0.837^{* *}$ & $-0.802^{* *}$ & -0.318 & -0.321 \\
$\Phi_{\mathrm{E} 0}$ & $0.964^{* *}$ & 1 & 0.623 & 0.623 & $0.910^{* *}$ & 1 & 0.509 & 0.512 \\
\hline
\end{tabular}

The JIP-test can be used as a tool to detect and quantify the changes in photosynthetic apparatus under heavy metal stress (Kalaji and Loboda 2007, Leplat et al. 2016). The increased $F_{0}$ and the decreased $F_{M}$ can be observed in this study for both trees in L1 and L2 treatment on day 10 and day 30 (Fig. $2 A, D, F, D$ ). This phenomenon is most apparent in L2 treatment groups on day 30. According to previous studies (Yamane et al. 1997, Kalaji et al. 2017), these results may suggest that the increased $F_{0}$ and decreased $F_{M}$ might be related to the inactivation of the PSII reaction center and the destabilization of PSII. The significant increase in both $\mathrm{ABS} / \mathrm{RC}$ and $\mathrm{TR}_{0} / \mathrm{RC}$ (Table 3 ) might indicate inactivation of a certain part of PSII RCs, which was most likely due to inactivation of the OEC as well as the transformation of active RCs to silent ones (Strasser et al. 2004, Zhang et al. 2017). Additionally, the significant increase in $\mathrm{ABS} / \mathrm{RC}$ and the positive L-band reflect the loss of connectivity and PSII RCs become more vulnerable to damage (Li et al. 2010). As a result, the $\mathrm{DI}_{0} / \mathrm{RC}$ increased significantly in L2 treatment on day 30 in both tested trees. Combined with the changes in the above parameters, $\mathrm{Mn}$ caused a decrease in overall PSII activity supported by the significant decrease in $\mathrm{PI}_{\mathrm{ABS}}$ (Fig. $3 B$ ).

Mn-excess affected the oxidation and reduction of PSI: The IP-phase is associated with the number of reduced end acceptors at the PSI acceptor side, and the reduced $\delta_{\mathrm{R} 0}$ represents the electron flow to the PSI acceptor side if inhibited (Li et al. 2010, Desotgiu et al. 2012). The reduction in amplitude of the IP-phase (Fig. $2 D, I)$ and $\delta_{\mathrm{R} 0}$ (Fig. $3 H$ ) may be caused by the inactivation of the PSI acceptor side or the inhibition in electron transport from the donor side of PSII to the acceptor side of PSI. In this study, with an increase of Mn concentration and stress duration, it can be observed that the 820 -nm absorption value of the fast phase gradually decreased, indicating that the rate of independent oxidation and reduction of P700 slowed down before electron transport from PSII to P700 (Gao et al. 2014). This phenomenon was supported by the significant decrease in $\mathrm{V}_{\mathrm{PSI}}$ in $M$. azedarach in the L2 treatment group on day 30 , indicating that the photochemical activity of PSI decreased. Furthermore, the reoxidation rate of $\mathrm{PQH}_{2}$ after illumination was affected by Mn stress (Table 2). Similarly, the $\mathrm{V}_{\mathrm{PSI}+\mathrm{PSII}}$ also decreased significantly in $M$. azedarach in the L1 and L2 treatment groups on day 30, which means that the rate of electron reoxidation and reduction of P700 and PC from PSII slowed down, and the coordination of electron transport between the PSI and PSII decreased. $\mathrm{V}_{\mathrm{PSII}}$ represents the rate of electron transfer from PSII to P700 (Fig. 2E,J). The significant decrease of $\mathrm{V}_{\text {PSII }}$ in $M$. azedarach in the $\mathrm{L} 2$ treatment group on day 30 reflected that the electron transfer from $\mathrm{PQH}_{2}$ to PSI was blocked 
due to the disordering of electron transport downstream of $\mathrm{Q}_{\mathrm{A}}$ (Fig. 2E,J; Table 2). Mn stress decreased the PSII activity, inhibited the re-reduction of P700, and affected the ability of electron transfer on the acceptor side of PSII (included the PSI), suggesting that the connectivity between PSI and PSII was damaged under Mn excess in $M$. azedarach in the L1 and L2 treatment groups on day 30 (Fig. $2 E, J)$. But in L. lucidum, the parameters ( $\mathrm{V}_{\mathrm{PSI}}$, $\mathrm{V}_{\text {PSI+PSII }}, \mathrm{V}_{\text {PSII }}$ ) decreased but not significantly; this may be because PSI still maintains activity under Mn stress (Fig. 2E,J; Table 2) (Gao et al. 2014, Chu et al. 2018).

Mn excess affected the leaf $\mathrm{CO}_{2}$ assimilation: Great decreases in net photosynthetic rate $\left(P_{\mathrm{N}}\right)$ and leaf $\mathrm{CO}_{2}$ assimilation (CE) in the L2 groups revealed the vulnerability of photosynthesis in M. azedarach and L. lucidum to Mn treatment (Table 1). In a previous investigation, Li et al. (2010) have shown that the decrease in CE in response to excess $\mathrm{Mn}$ is caused by impaired electron transport capacity rather than stomatal factors. In the current study, since the decrease in stomatal conductance $\left(g_{\mathrm{s}}\right)$ was accompanied by an increase in intercellular $\mathrm{CO}_{2}$ concentration $\left(C_{\mathrm{i}}\right)$ (Table 1$)$, Mn excess caused nonstomatal factors to impact photosynthesis in $M$. azedarach and L. lucidum (Xie et al. 2018).

Jiang et al. (2008) have found that the decreased CE in response to aluminum (Al) stress for the impaired electron transport chain is accompanied by the limitation in the reduction of the PSI end electron acceptors through the positive relationship between $\mathrm{CE}$ and the IP-phase. In L. lucidum, the decrease of CE was significantly and negatively related to the increase of the Mn concentration, but significantly and positively related to the decrease of $\mathrm{PI}_{\mathrm{ABS}}$ on day 30 (Table 4). There was no significant relationship between the $\mathrm{CE}$ and $\mathrm{V}_{\mathrm{PSI}}$ or the Mn concentration and $\mathrm{V}_{\mathrm{PSI}}$. These results suggest that excess $\mathrm{Mn}$ impaired the activity of PSII but the PSI of L. lucidum was stable under the Mn excess. The decrease in CE might be related to the damage of PSII and the electron transport chain from the donor side of PSII to $\mathrm{Q}_{\mathrm{A}}$. However, different results were shown in $M$. azedarach. In $M$. azedarach, the $\mathrm{Mn}$ concentrations in leaves were significantly and negatively related to $\mathrm{PI}_{\mathrm{ABS}}, \mathrm{V}_{\mathrm{PSI}}, \mathrm{V}_{\mathrm{PSII}}$, and $\Phi_{\mathrm{E} 0}$, while $\mathrm{CE}$ was significantly and positively related to $\mathrm{PI}_{\mathrm{ABS}}, \mathrm{V}_{\mathrm{PSI}}, \mathrm{V}_{\mathrm{PSII}}$, and $\Phi_{\mathrm{E} 0}$ (Table 4). These results suggest that the excess Mn damaged the activity of PSII and changed the state of oxidation and reduction of PSI. As a result, it further affected the electron transfer chain and its stability between PSII and PSI. The decreased CE might be related to the damaged electron transfer chain and the inactive PSII and the state of oxidation and reduction of PSI.

Notably, reduction of $P_{\mathrm{N}}$ and CE was more significant under Mn excess in the L2 treatment group in $M$. azedarach than in L. lucidum (Table 1). This phenomenon may be caused by the fact that when compared to M. azedarach, L. lucidum still maintained relatively stable photosynthetic capacity and showed better tolerance under the Mn excess. Another possible reason is that the translation factor of $M$. azedarach was higher than that of L. lucidum, indicating that more $\mathrm{Mn}^{2+}$ was transported from the roots to the leaves in M. azedarach. This result was consistent with the findings of Bernardini et al. (2016) that zinc is transported to the leaves of plants, leading to the decrease of CE, while lead $(\mathrm{Pb})$ was accumulated mainly in the roots, which has a slight effect on gas-exchange parameters.

Conclusions: In this study, we concluded that excess Mn harmed photosynthesis in L. lucidum and M. azedarach. The reduction in leaf $\mathrm{CO}_{2}$ assimilation and the net photosynthetic rates in both tested trees were mainly caused by the damage of the photosynthetic electron transport chain from the donor side of PSII to the reduction of end acceptors of PSI. The change of the specific energy fluxes (per active PSII) suggested that the reaction center of PSII was inactivated under Mn excess in both tested trees. Mn excess decreased the activity of PSII owing to the inactive OEC and the limitation in electron transport downstream of $\mathrm{Q}_{\mathrm{A}}^{-}$in both tested trees. The state of the oxidation and reduction in PSI under Mn was different in both tested tree species. The rate of photochemical activity of PSI decreased (only in $M$. azedarach) for the independent oxidation while reduction of P700 was slowed down. Comparatively, Mn stress exerted less inhibitory effects on photosynthesis in L. lucidum. Therefore, the photosynthetic performance showed more tolerance in L. lucidum compared to M. azedarach under Mn stress.

\section{References}

Aranjuelo I., Doustaly F., Cela J. et al.: Glutathione and transpiration as key factors conditioning oxidative stress in Arabidopsis thaliana exposed to uranium. - Planta 239: 817830, 2014.

Barón M., Arellano J.B., Gorgé J.L.: Copper and photosystem II: A controversial relationship. - Physiol. Plantarum 94: 174180, 1995

Belatik A., Hotchandani S., Tajmir-Riahi H.A., Carpentier R.: Alteration of the structure and function of photosystem I by $\mathrm{Pb}^{2+}$. - J. Photoch. Photobio. B 123: 41-47, 2013.

Bernardini A., Salvatori E., Guerrini V. et al.: Effects of high $\mathrm{Zn}$ and $\mathrm{Pb}$ concentrations on Phragmites australis (Cav.) Trin. Ex. Steudel: Photosynthetic performance and metal accumulation capacity under controlled conditions. - Int. J. Phytoremediat. 18: 16-24, 2016.

Ceppi M.G., Oukarroum A., Çiçek N. et al.: The IP amplitude of the fluorescence rise OJIP is sensitive to changes in the photosystem I content of leaves: a study on plants exposed to magnesium and sulfate deficiencies, drought stress and salt stress. - Physiol. Plantarum 144: 277-288, 2012.

Chang W., Chen C., Dong H., Zhang C.: Artificial Mn4-oxido complexes mimic the oxygen-evolving center in photosynthesis. - Sci. Bull. 62: 665-668, 2017.

Che X.K., Ding R.R., Li Y.T. et al.: Mechanism of long-term toxicity of $\mathrm{CuO}$ NPs to microalgae. - Nanotoxicology 12: 923-939, 2018.

Chu J.J., Zhu F., Chen X.Y. et al.: Effects of cadmium on photosynthesis of Schima superba young plant detected by chlorophyll fluorescence. - Environ. Sci. Pollut. R. 25: 10679-10687, 2018.

Demmig-Adams B., Stewart J.J., Adams III W.W.: Environmental regulation of intrinsic photosynthetic capacity: an integrated view. - Curr. Opin. Plant Biol. 37: 34-41, 2017.

Desotgiu R., Pollastrini M., Cascio C. et al:: Chlorophyll a 
fluorescence analysis along a vertical gradient of the crown in a poplar (Oxford clone) subjected to ozone and water stress. Tree Physiol. 32: 976-986, 2012.

Dewez D., Geoffroy L., Vernet G., Popovic R.: Determination of photosynthetic and enzymatic biomarkers sensitivity used to evaluate toxic effects of copper and fludioxonil in alga Scenedesmus obliquus. - Aquat. Toxicol. 74: 150-159, 2005.

Farmer E.E., Mueller M.J.: ROS-mediated lipid peroxidation and RES-activated signaling. - Annu. Rev. Plant Biol. 64: 429450, 2013.

Flexas J., Medrano H.: Drought-inhibition of photosynthesis in $\mathrm{C}_{3}$ plants: Stomatal and non-stomatal limitations revisited. Ann. Bot.-London 89: 183-189, 2002.

Fodor F.: Physiological responses of vascular plants to heavy metals. - In: Prasad M.N.V., Strzałka K. (ed.): Physiology and Biochemistry of Metal Toxicity and Tolerance in Plants. Pp. 149-177. Springer, Dordrecht 2002.

Gao J., Li P.M., Ma F.W., Goltsev V.: Photosynthetic performance during leaf expansion in Malus micromalus probed by chlorophyll $a$ fluorescence and modulated $820 \mathrm{~nm}$ reflection. J. Photoch. Photobio. B 137: 144-150, 2014.

Gomes M.T.G., da Luz A.C., dos Santos M.R. et al.: Drought tolerance of passion fruit plants assessed by the OJIP chlorophyll $a$ fluorescence transient. - Sci. Hortic.-Amsterdam 142: 49-56, 2012.

González E., Lynch J.: Effects of manganese toxicity on leaf $\mathrm{CO}_{2}$ assimilation of contrasting common bean genotypes. Physiol. Plantarum 101: 872-880, 2006.

Gururani M.A., Upadhyaya C.P., Strasser R.J. et al.: Evaluation of abiotic stress tolerance in transgenic potato plants with reduced expression of PSII manganese stabilizing protein. Plant. Sci. 198: 7-16, 2013.

Han Y.L., Zhang L.L., Yang Y.H. et al.: Pb uptake and toxicity to Iris halophila tested on $\mathrm{Pb}$ mine tailing materials. - Environ. Pollut. 214: 510-516, 2016.

He B., Yun Z.J., Shi J.B., Jiang G.B.: Research progress of heavy metal pollution in China: Sources, analytical methods, status, and toxicity. - Chinese Sci. Bull. 58: 134-140, 2012.

Huang W., Zhang S.B., Liu T.: Moderate photoinhibition of photosystem II significantly affects linear electron flow in the shade-demanding plant Panax notoginseng. - Front. Plant Sci. 9: 637, 2018.

Jiang H.X., Chen L.S., Zheng J.G. et al:: Aluminum-induced effects on Photosystem II photochemistry in Citrus leaves assessed by the chlorophyll $a$ fluorescence transient. - Tree Physiol. 28: 1863-1871, 2008.

Kalaji H.M., Loboda T.: Photosystem II of barley seedlings under cadmium and lead stress. - Plant Soil Environ. 53: 511-516, 2007.

Kalaji H.M., Schansker G., Brestič M. et al.: Frequently asked questions about chlorophyll fluorescence, the sequel. Photosynth. Res. 132: 13-66, 2017.

Khattak M.I., Jabeen R.: Detection of heavy metals in leaves of Melia azedarach and Eucalyptus citriodora as biomonitoring tools in the region of Quetta valley. - Pak. J. Bot. 44: 675-681, 2012.

Kitao M., Lei T.T., Koike T.: Effects of manganese toxicity on photosynthesis of white birch (Betula platyphylla var. japonica) seedlings. - Physiol. Plantarum 101: 249-256, 1997.

Kono M., Noguchi K., Terashima I.: Roles of the cyclic electron flow around PSI (CEF-PSI) and $\mathrm{O}_{2}$-dependent alternative pathways in regulation of the photosynthetic electron flow in short-term fluctuating light in Arabidopsis thaliana. - Plant Cell Physiol. 55: 990-1004, 2014.

Leplat F., Pedas P.R., Rasmussen S.K., Husted S.: Identification of manganese efficiency candidate genes in winter barley
(Hordeum vulgare) using genome wide association mapping. - BMC Genomics 17: 775, 2016.

Li Q., Chen L.S., Jiang H.X. et al.: Effects of manganese-excess on $\mathrm{CO}_{2}$ assimilation, ribulose-1,5-bisphosphate carboxylase/ oxygenase, carbohydrates and photosynthetic electron transport of leaves, and antioxidant systems of leaves and roots in Citrus grandis seedlings. - BMC Plant Biol. 10: 42, 2010.

Li X., Zhang L.: Endophytic infection alleviates $\mathrm{Pb}^{2+}$ stress effects on photosystem II functioning of Oryza sativa leaves. J. Hazard. Mater. 295: 79-85, 2015.

Liang H.Z., Zhu F., Wang R.J. et al.: Photosystem II of Ligustrum lucidum in response to different levels of manganese exposure. - Sci. Rep.-UK 9: 12568, 2019.

Lin M.Z., Jin M.F.: Soil $\mathrm{Cu}$ contamination destroys the photosynthetic systems and hampers the growth of green vegetables. - Photosynthetica 56: 1336-1345, 2018.

Macfie S.M., Taylor G.J.: The effects of excess manganese on photosynthetic rate and concentration of chlorophyll in Triticum aestivum grown in solution culture. - Physiol. Plantarum 85: 467-475, 1992.

Mehta P., Jajoo A., Mathur S., Bharti S.: Chlorophyll a fluorescence study revealing effects of high salt stress on Photosystem II in wheat leaves. - Plant Physiol. Bioch. 48: 16-20, 2010.

Millaleo R., Reyes-Díaz M., Alberdi M. et al.: Excess manganese differentially inhibits photosystem I versus II in Arabidopsis thaliana. - J. Exp. Bot. 64: 343-354, 2013.

Miyata K., Ikeda H., Nakaji M. et al.: Rate constants of PSII photoinhibition and its repair, and PSII fluorescence parameters in field plants in relation to their growth light environments. - Plant Cell Physiol. 56: 1841-1854, 2015.

Mlinarić S., Antunović Dunić J., Skendrović Babojelić M. et al.: Differential accumulation of photosynthetic proteins regulates diurnal photochemical adjustments of PSII in common fig (Ficus carica L.) leaves. - J. Plant Physiol. 209: 1-10, 2017.

Moradi L., Ehsanzadeh P.: Effects of Cd on photosynthesis and growth of safflower (Carthamus tinctorius L.) genotypes. Photosynthetica 53: 506-518, 2015.

Nagajyoti P.C., Lee K.D., Sreekanth T.V.M.: Heavy metals, occurrence and toxicity for plants: a review. - Environ. Chem. Lett. 8: 199-216, 2010.

Pätsikkä E., Aro E.-M., Tyystjärvi E.: Increase in the quantum yield of photoinhibition contributes to copper toxicity in vivo. - Plant Physiol. 117: 619-627, 1998.

Qiao X.Q., Shi G.X., Jia R. et al.: Physiological and biochemical responses induced by lead stress in Spirodela polyrhiza. Plant Growth. Regul. 67: 217-225, 2012.

Rijstenbil J.W., Derksen J.W.M., Gerringa L.J.A. et al.: Oxidative stress induced by copper: defense and damage in the marine planktonic diatom Ditylum brightwellii, grown in continuous cultures with high and low zinc levels. - Mar. Biol. 119: 583$590,1994$.

Schmidt S.B., Powikrowska M., Krogholm K.S. et al.: Photosystem II functionality in barley responds dynamically to changes in leaf manganese status. - Front. Plant Sci. 7: $1772,2016$.

Sigfridsson K.G.V., Bernát G., Mamedov F., Styring S.: Molecular interference of $\mathrm{Cd}^{2+}$ with photosystem II. BBA-Bioenergetics 1659: 19-31, 2004.

Stirbet A., Lazár D., Kromdijk J., Govindjee: Chlorophyll $a$ fluorescence induction: Can just a one-second measurement be used to quantify abiotic stress responses? - Photosynthetica 56: 86-104, 2018.

Stirbet A., Riznichenko G.Yu., Rubin A.B., Govindjee: Modeling chlorophyll $a$ fluorescence transient: Relation to 
photosynthesis. - Biochemistry-Moscow+ 79: 291-323, 2014.

Strasser B.J.: Donor side capacity of Photosystem II probed by chlorophyll $a$ fluorescence transient. - Photosynth. Res. 52: 147-155, 1997.

Strasser R.J., Srivastava A., Govindjee: Polyphasic chlorophyll $a$ fluorescence transient in plants and cyanobacteria. Photochem. Photobiol. 61: 32-42, 1995.

Strasser R.J., Tsimilli-Michael M., Qiang S., Goltsev V.: Simultaneous in vivo recording of prompt and delayed fluorescence and 820-nm reflection changes during drying and after rehydration of the resurrection plant Haberlea rhodopensis. - BBA-Bioenergetics 1797: 1313-1326, 2010.

Strasser R.J., Tsimilli-Michael M., Srivastava A.: Analysis of the chlorophyll $a$ fluorescence transient. - In: Papageorgiou G.C., Govindjee (ed.): Chlorophyll $a$ Fluorescence: A Signature of Photosynthesis. Advances in Photosynthesis and Respiration. Pp. 321-362. Springer, Dordrecht 2004.

Su M.J., Cai S.Z., Deng H.M. et al.: [Effects of cadmium and acid rain on cell membrane permeability and osmotic adjustment substance content of Melia azedarach L. seedlings.] Acta Sci. Circum. 37: 4436-4443, 2017. [In Chinese] doi: $10.13671 / \mathrm{j} . h j k x x b .2017 .0216$.

Suorsa M., Järvi S., Grieco M. et al.: PROTON GRADIENT REGULATION5 is essential for proper acclimation of Arabidopsis photosystem I to naturally and artificially fluctuating light conditions. - Plant Cell 24: 2934-2948, 2012.

Suresh R., Foy C.D., Weidner J.R.: Effects of excess soil manganese on stomatal function in two soybean cultivars. J. Plant Nutr. 10: 749-760, 1987.

Tikkanen M., Mekala N.R., Aro E.-M.: Photosystem II photoinhibition-repair cycle protects Photosystem I from irreversible damage. - BBA-Bioenergetics 1837: 210-215, 2014.

Tong F.P., Long Y.Z., Yi J.X. et al.: Characteristics of heavy metal accumulation in Broussonetia papyrifera in an antimony mine. - J. Food Agric. Environ. 9: 701-705, 2011.

Trikshiqi R., Rexha M.: Heavy metal monitoring by Ligustrum lucidum, Fam: Oleaceae vascular plant as bio-indicator in Durres city. - Int. J. Curr. Res. 7: 14415-14422, 2015.

Valladares F., Pearcy R.W.: Drought can be more critical in the shade than in the sun: a field study of carbon gain and photo-inhibition in a Californian shrub during a dry El Niño year. - Plant Cell Environ. 25: 749-759, 2002.

Xie D.F., Zhang G.C., Xia X.X. et al.: The effects of phenolic acids on the photosynthetic characteristics and growth of Populus $\times$ euramericana cv. 'Neva' seedlings. Photosynthetica 56: 981-988, 2018.

Xue S., Zhu F., Wu C. et al.: Effects of manganese on the microstructures of Chenopodium ambrosioides L., a manganese tolerant plant. - Int. J. Phytoremediat. 18: 710-719, 2015.

Yamane Y., Kashino Y., Koike H., Satoh K.: Increases in the fluorescence $\mathrm{F}_{\mathrm{O}}$ level and reversible inhibition of Photosystem II reaction center by high-temperature treatments in higher plants. - Photosynth. Res. 52: 57-64, 1997.

Yang Y.J., Liu T., Zhang S.B., Huang W.: Photoinhibition of oxygen-evolving complex and photosystem II at chilling stress in the tropical tree species Dalbergia odorifera. Photosynthetica 58: 245-252, 2020.

Yruela I., Pueyo J.J., Alonso P.J., Picorel R.: Photoinhibition of photosystem II from higher plants: Effect of copper inhibition. - J. Biol. Chem. 271: 27408-27415, 1996.

Zhang L.T., Su F., Zhang C.H. et al.: Changes of photosynthetic behaviors and photoprotection during cell transformation and astaxanthin accumulation in Haematococcus pluvialis grown outdoors in tubular photobioreactors. - Int. J. Mol. Sci. 18: 33, 2017.

Zhang Z.S., Jin L.Q., Li Y.T. et al.: Ultraviolet-B radiation (UV-B) relieves chilling-light-induced PSI photoinhibition and accelerates the recovery of $\mathrm{CO}_{2}$ assimilation in cucumber (Cucumis sativus L.) leaves. - Sci. Rep.-UK 6: 34455, 2016.

(C) The authors. This is an open access article distributed under the terms of the Creative Commons BY-NC-ND Licence. 